\title{
Możliwości słuchowe dorosłych osób ogłuchłych zaopatrzonych w implant ślimakowy
}

\section{Auditory skills of deaf people provided with cochlear implants}

\author{
Joanna Rostkowska ${ }^{1,2}$, Beata Wojewódzka ${ }^{1,2}$, Joanna Kobosko ${ }^{1,2}$, \\ Anna Geremek-Samsonowicz ${ }^{1,2}$, Henryk Skarżyński ${ }^{1,2}$ \\ ${ }^{1}$ Instytut Fizjologii i Patologii Słuchu, ul. Zgrupowania AK „Kampinos” 1, 01-943 Warszawa \\ ${ }^{2}$ Światowe Centrum Słuchu, ul. Mokra 17, Kajetany, 05-830 Nadarzyn \\ Adres autora: Joanna Rostkowska, Instytut Fizjologii i Patologii Słuchu, Klinika Rehabilitacji, \\ ul. Zgrupowania AK „Kampinos” 1, 01-943 Warszawa, tel. 505977 468, e-mail: j.rostkowska@ifps.org.pl
}

\section{Streszczenie}

Wstęp: Nabyte dzięki wszczepowi ślimakowemu możliwości słuchowe pacjentów z głuchotą postlingwalną są bazą dla działań rehabilitacyjnych sprzyjających rozwojowi percepcji słuchowej i umożliwiających odbiór mowy na drodze słuchowej.

Cel pracy: Celem pracy jest przedstawienie poziomu percepcji słuchowej uzyskiwanej przez dorosłych, implantowanych, postlingwalnie ogłuchłych pacjentów.

Materiał i metody: Badaniami objęto 40 dorosłych pacjentów implantowanych, ogłuchłych postlingwalnie. Do pomiaru rozwoju i postępu możliwości słuchowych po operacji wszczepienia systemu implantu ślimakowego, w określonych odstępach czasowych: 1, 3, 6, 12 miesięcy, zastosowano 5 podtestów z baterii testów opracowanych przez firme MED-EL.

Wyniki: Wyniki badań wskazują na największy przyrost możliwości słuchowych w pierwszych trzech miesiącach od podłączenia procesora mowy. Najtrudniejsza okazała się dla pacjentów próba oceniająca stopień identyfikacji słuchowej spółgłosek polskich w izolacji. W zakresie identyfikacji słuchowej liczb, już po pierwszym podłączeniu procesora mowy, pacjenci uzyskiwali ponad $97 \%$ poprawnych odpowiedzi.

Wnioski: Otrzymane wyniki umożliwiają prognozowanie postępów w toku rehabilitacji po wszczepieniu implantu ślimakowego. Wiedzę tę można wykorzystać także w trakcie diagnostyki w kierunku zastosowania systemu implantu ślimakowego (CI), informując pacjenta o możliwościach rozwoju percepcji słuchowej i monitorowania postępów uzyskiwanych po zastosowaniu CI.

Słowa kluczowe: implanty ślimakowe • słuchowa percepcja mowy • rehabilitacja • głuchota postlingwalna • umiejętności słuchowe

\section{Abstract}

Background: Hearing abilities of patients with the postlingual deafness, developed thanks to the cochlear implant, are the basis for the rehabilitation conductive to the development of the auditory perception and enabling them the auditory speech reception.

Aim: The aim of this study was to present the level of the auditory perception achieved by the adult, postlingually deafened cochlear implant patients.

Material and methods: The study included 40 adult cochlear implant patients postlingually deafened. The assessment of the development and progress of their auditory skills after the cochlear implant surgery, in stated intervals of 1, 3, 6 and months, was performed using 5 sub-tests from the battery of tests developed by the MED-EL Company (Innsbruck, Austria).

Results: Results show that the greatest progress in auditory abilities happens in the first three months after the first fitting of the speech processor. The most difficult for cochlear implant patients came out to be the test assessing the level 
of the auditory recognition of Polish consonants in isolation. As concerns the auditory recognition of numbers, already after the first fitting of the speech processor the patients were able to achieve more than $97 \%$ of the correct replies.

Conclusions: The results allow us to predict the progress of rehabilitation after cochlear implantation. This knowledge could also be useful in the diagnostics for cochlear implantation, informing the patient about the possibilities for developing the auditory perception, as well as for the monitoring of progress after cochlear implantation.

Key words: cochlear implants • auditory speech perception • rehabilitation • postlingual deafness • auditory skills

\section{Wstęp}

Osoby postlingwalnie ogłuchłe, tj. takie które utraciły słuch po opanowaniu mowy stanowią szczególną grupę pacjentów ze względu na zachowaną pamięć doświadczeń słuchowych, w tym języka. Są to pacjenci, dla których interwencja medyczna w postaci zastosowania systemu implantu ślimakowego stała się standardowym rozwiązaniem. W Polsce program leczenia głuchoty tą metodą rozpoczęto w 1992 roku [Skarżyński, Szuchnik, \& Malesińska, 2004]. Programem tym objęci są pacjenci prelingwalni, perilingwalni i postlingwalni, zarówno dzieci jak i dorośli [Szuchnik, Piotrowska, Lorens, \& Wojewódzka, 2001; Szuchnik, Święcicka, Lorens, \& Skarżyński, 1997]. Szczególną grupę pacjentów stanowią osoby dorosłe z głuchotą postlingwalną, którzy mają zazwyczaj wysokie oczekiwania co do efektów rehabilitacji pooperacyjnej.

Celem artykułu jest ocena poziomu percepcji słuchowej uzyskiwanej przez pacjentów postlingwalnych, użytkowników implantu ślimakowego, na przestrzeni roku od momentu podłączenia procesora mowy, w ustalonych odstępach czasowych. Do tej pory tak duża i jednorodna grupa postlingwalnych implantowanych pacjentów nie została opisana w literaturze polskiej [Wojewódzka, 2009]. Analiza pozwoli na weryfikację i dobór specyficznych materiałów dydaktycznych pozwalających na efektywniejszy trening słuchowy, dostosowany do potrzeb, dobranych według stopnia trudności i interwałów czasowych.

\section{Materiał i metoda}

W badaniach uczestniczyło 40 pacjentów implantowanych: $21(52,5 \%)$ kobiet i 19 (47,5\%) mężczyzn. Wszyscy badani to osoby dorosłe, ogłuchłe postlingwalnie tj. po ukończeniu 6 roku życia. Różni je czas trwania uszkodzenia słuchu od 6 miesięcy do 25 lat (Tabela 1).

Tabela 1. Rozkład czasu przebywania w świecie ciszy pacjentów zaopatrzonych w system implantu ślimakowego

\begin{tabular}{ccc}
\hline $\begin{array}{c}\text { Przedział czasowy } \\
\text { (lata) }\end{array}$ & Liczebność & Procent (\%) \\
\hline $0-1$ & 2 & 5 \\
\hline $2-4$ & 6 & 15 \\
\hline $5-8$ & 10 & 25 \\
\hline $9-15$ & 17 & 42,5 \\
\hline $15-20$ & 4 & 10 \\
\hline $24-25$ & 1 & 2,5 \\
\hline
\end{tabular}

Tabela 2. Wiek pacjentów w momencie implantacji

\begin{tabular}{ccc}
\hline $\begin{array}{c}\text { Przedziat wiekowy } \\
\text { (lata) }\end{array}$ & Liczebnośćc & Procent (\%) \\
\hline $27-30$ & 4 & 10 \\
\hline $31-40$ & 6 & 15 \\
\hline $41-50$ & 6 & 15 \\
\hline $51-60$ & 16 & 40 \\
\hline $61-70$ & 6 & 15 \\
\hline $71-78$ & 2 & 5 \\
\hline
\end{tabular}

Tabela 3. Przyczyny głuchoty u pacjentów zaopatrzonych w system implantu ślimakowego

\begin{tabular}{lcc}
\hline Przyczyna utraty słuchu & Liczebność & Procent (\%) \\
\hline $\begin{array}{l}\text { Zapalenie opon } \\
\text { mózgowych }\end{array}$ & 17 & 42,5 \\
\hline $\begin{array}{l}\text { Przyjmowanie leków } \\
\text { ototoksycznych }\end{array}$ & 16 & 40 \\
\hline Urazy & 10 & 25 \\
\hline $\begin{array}{l}\text { Przewlekłe stany zapalne } \\
\text { ucha }\end{array}$ & 4 & 10 \\
\hline $\begin{array}{l}\text { Niedosłuch postępujący } \\
\text { o nieustalonej etiologii }\end{array}$ & 2 & 5 \\
\hline Otoskleroza & 1 & 2,5 \\
\hline
\end{tabular}

Tabela 4. Typy zastosowanych systemów implantów ślimakowych u pacjentów

\begin{tabular}{ccc}
\hline $\begin{array}{c}\text { Typ systemu implantu } \\
\text { ślimakowego }\end{array}$ & Liczebność & Procent \\
\hline MED-EL C40 & 15 & 37,5 \\
\hline MED-EL C40+ & 13 & 32,5 \\
\hline Nucleus & 9 & 22,5 \\
\hline Laura & 3 & 7,5 \\
\hline
\end{tabular}

Wiek pacjentów w momencie implantacji wynosi od 27 do 78 lat, średnio 51,2 lata (Tabela 2).

Moment utraty słuchu został jednoznacznie określony przez 34 pacjentów, natomiast u 6 osób następowała stopniowa utrata słuchu. Najczęstszą przyczyną głuchoty było zapalenie opon mózgowych $(42,5 \%)$ oraz przyjmowanie leków ototoksycznych (40\%) (Tabela 3).

Wszyscy pacjenci implantowani byli użytkownikami różnych typów wielokanałowych systemów implantów ślimakowych (Tabela 4). 


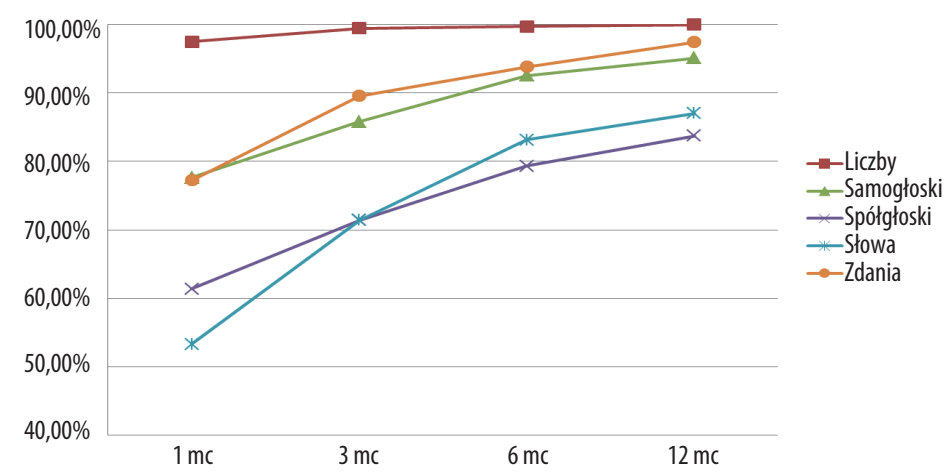

Rycina 1. Przyrost umiejętności słuchowych w zakresie rozpoznawania: samogłosek, spółgłosek, słów, zdań i liczb (testy MED-EL)

W celu opisu, oceny i analizy percepcji słuchowej wykorzystano baterię testów firmy MED-EL, przeznaczoną dla pacjentów z głuchotą postlingwalną, w wersji dostosowanej do języka polskiego. Wszystkie zadania zawarte w testach opierają się wyłącznie na odbiorze słuchowym, tzn. uzyskanym bez pomocy bodźców wzrokowych. Podczas badania wykorzystuje się w tym celu okrągłą ramkę wypełnioną odpowiednim materiałem, służącą do zasłonięcia ust (aż do wysokości oczu) tak, aby uniemożliwić odczytanie dodatkowej informacji na drodze wzrokowej.

Przygotowanie do testu i zaznajomienie z nim pacjenta może być prowadzone poprzez komunikację na drodze wzrokowo-słuchowej z poparciem gestów. W przypadku, kiedy to konieczne, można użyć instrukcji na piśmie.

Dla każdego testu dostępne są listy głosek, liczb i wyrazów dobranych losowo. Ważne jest, aby badany nie był w stanie przewidzieć kolejnego zadania testu. Kolejność wykonywania testów jest dowolna. Pacjentów zaopatrzonych w system implantu ślimakowego badano po miesiącu od pierwszego podłączenia urządzenia, następnie po 3, 6 i 12 miesiącach.

Zestaw testów MED-EL składa się z pięciu podtestów zawierających zadania, których wskaźnikiem wykonania jest procent poprawnie podanych odpowiedzi:

1. Test identyfikacji samogłosek języka polskiego w sylabach - test składa się z 15 list, w każdej po 8 samogłosek występujących pomiędzy spółgłoskami. Prezentowane są 3 losowo wybrane listy. Zadaniem pacjenta jest powtórzenie usłyszanych raz sylab.

2. Test identyfikacji spółgłosek języka polskiego w sylabach - test składa się z 10 list po 16 spółgłosek znajdujących się pomiędzy samogłoskami. Prezentowane są 3 losowo wybrane listy. Zadaniem pacjenta jest powtórzenie usłyszanych raz sylab.

3. Test identyfikacji liczb od 1 do 100 - test składa się 15 list po 10 liczb. Prezentowane są 4 losowo wybrane listy. Zadaniem pacjenta jest powtórzenie usłyszanej raz liczby.

4. Test identyfikacji słów jednosylabowych - test składa się z 10 list po 20 słów jednosylabowych w każdej. Prezentowane są 3 losowo wybrane listy. Zadaniem pacjenta jest powtórzenie usłyszanego raz wyrazu.

5. Test rozumienia zdań w zestawach otwartych - test składa się ze 160 zdań umieszczonych na 16 listach po 10 zdań. Każda lista zawiera 53 słowa w zdaniach od 3 do 8-wyrazowych. Pacjent ma powtórzyć całe zdanie po jednorazowej prezentacji.

\section{Wyniki}

Przyrost umiejętności słuchowych ocenianych na podstawie wykonania baterii testów MED-EL został przedstawiony w formie graficznej na Rycinie 1 .

Wykresy te pokazują przyrost umiejętności słuchowych w odniesieniu do identyfikacji samogłosek (test 1), spółgłosek (test 2), liczb (test 3), słów (test 4) i zdań (test 5). Korzyści wynikające ze stosowania implantu widoczne są już po miesiącu użytkowania procesora mowy, kiedy nie są jeszcze uaktywnione wszystkie elektrody. Rozrzut wyników w poszczególnych testach na tym etapie dochodzi do $24 \%$ i związany jest $\mathrm{z}$ różnym stopniem trudności zadań słuchowych. Najtrudniejsze do percepcji słuchowej słowa jednosylabowe identyfikowane są w 53,3\%. Rozpoznawanie zdań i samogłosek kształtuje się na poziomie $78 \%$.

Wyraźny przyrost korzyści słuchowych w zakresie 10-20\% dla głosek, słów i zdań, obserwuje się między pierwszym a trzecim miesiącem użytkowania procesora mowy. W 6 miesiącu od podłączenia urządzenia przyrost umiejętności słuchowych w stosunku do 3 miesiąca spada. W 12 miesiącu względem wyjściowych umiejętności słuchowych obserwuje się korzyści słuchowe osiągające dla: samogłosek 95,08\%, spółgłosek 83,73\%, słów 87,05\% oraz zdań 97,44\%. Odmienny przyrost umiejętności słuchowych prezentuje test liczb. Już po miesiącu wynosi $97,48 \%$ poprawnych odpowiedzi, a w czasie ostatniego badania wszyscy pacjenci osiągnęli $100 \%$ wykonania testu.

\section{Dyskusja}

Implanty ślimakowe dają możliwość odbioru mowy na drodze słuchowej tuż po podłączeniu procesora mowy niezależnie od okresu przebywania „w świecie ciszy” i jest to moment, w którym należy rozpocząć rehabilitację. Roczny okres rehabilitacji słuchowej w grupie dorosłych pacjentów z głuchotą postlingwalną jest wystarczający do uzyskania maksymalnych wyników testów badających percepcję słuchową. Największy przyrost umiejętności słuchowych ma miejsce między pierwszym a trzecim miesiącem korzystania $\mathrm{z}$ procesora mowy. Jest to równocześnie okres intensywnej rehabilitacji słuchowej. Korzyści słuchowe po sześciu miesiącach terapii logopedycznej są porównywalne z korzyściami po roku, co świadczy o osiągnięciu na tym etapie poziomu stabilizacji rozumienia mowy odbieranej wyłącznie na drodze słuchowej. 
Zbieżność przebiegu wykresów rozpoznawania samogłosek i zdań tłumaczy wpływ samogłosek na kontur intonacyjny wypowiedzi. W rozpoznawaniu zdań dodatkowo pomocny jest kontekst zdaniowy. Za podobieństwo krzywych spółgłosek i słów jednosylabowych odpowiedzialne są cechy dystynktywne spółgłosek. Jednakże to wysoki poziom rozumienia zdań $(97,44 \%$ po roku) ma bezpośredni korzystny wpływ na komunikacyjne funkcjonowanie osób implantowanych w życiu codziennym. Szczególnym przebiegiem charakteryzuje się krzywa dotycząca liczb - fiksacja ciągów liczbowych umożliwia już po miesiącu osiągnąć bardzo wysoki poziom $(97,48 \%)$.

\section{Wnioski}

Otrzymane wyniki badań umożliwiają prognozowanie rozwoju percepcji słuchowej po wszczepieniu systemu implantu ślimakowego u pacjentów w toku rehabilitacji. Wskazują newralgiczne przedziały czasowe w rozwoju percepcji słuchowej, w których powinna następować intensyfikacja treningu słuchowego. Na podstawie otrzymanych wyników można wysnuć wnioski na temat tego, jak długo powinien trwać trening słuchowy i w którym momencie należy rozpocząć rozważanie przeniesienia ciężaru terapii na psychoterapię pacjenta [Kobosko, Pankowska, \& Skarżyński, 2012].

Znajomość etapów rozwoju i badania poszczególnych umiejętności słuchowych pozwolą na dobór materiału odpowiedniego do pracy w gabinecie terapeutycznym i samodzielnej pracy pacjenta $\mathrm{w}$ domu.

Obraz symulacji rozwoju percepcji słuchowej po zastosowaniu systemu implantu ślimakowego powinien być znany pacjentowi już w toku postępowania diagnostycznego celem kwalifikacji do wszczepu, co niewątpliwie obniży poziom lęku i tym samym ułatwi podjęcie pacjentowi decyzji, skróci czas trwania diagnozy, a także będzie sprzyjać pozytywnej postawie do terapii słuchowej.

Umiejętności słuchowe osiągane dzięki zastosowaniu implantu ślimakowego ułatwiają funkcjonowanie w życiu codziennym wszystkim pacjentom, dając możliwość korzystania ze zmysłu, który osadza ich w akustycznym wymiarze otoczenia. Osiągany dzięki niemu poziom funkcjonowania słuchowego zwiększa niezależność społeczną i podwyższa jakość życia dorosłego pacjenta.

\section{Piśmiennictwo:}

1. Kobosko J., Pankowska A., Skarżyński H.: Strategie radzenia sobie ze stresem u osób postlingwalnie ogłuchłych korzystających z implantu ślimakowego w porównaniu z populacją ogólną słyszących. Otolaryngologia Polska, 2012; 66(2): 132-37

2. Skarżyński H., Szuchnik J., Malesińska M.: Implanty ślimakowe - rehabilitacja. Warszawa: Stowarzyszenie „Człowiek Człowiekowi”, 2004
3. Szuchnik J., Piotrowska A., Lorens A., Wojewódzka D.: Procedura przedoperacyjna kwalifikacji do wszczepienia implantu ślimakowego stosowana w Instytucie Fizjologii i Patologii Słuchu w Warszawie. Audiofonologia, 20, Lublin, 2001

4. Szuchnik J., Święcicka A., Lorens A., Skarżyński H.: Doświadczenia polskich pacjentów korzystających z wielokanałowego implantu COMBI-40, Audiofonologia, 11, Lublin, 1997

5. Wojewódzka D.: Umiejętności słuchowe osób ogłuchłych zaopatrzonych w implanty ślimakowe lub aparaty słuchowe. Nieopublikowana rozprawa doktorska. Warszawa: Akademia Pedagogiki Specjalnej, 2009 